\title{
MYSTERIES AND SCANDALS. TRANSCENDENTAL NATURALISM AND THE FUTURE OF PHILOSOPHY
}

\author{
DiANA I. PÉREZ \\ Departamento de Filosofía \\ Universidad de Buenos Aires \\ Consejo Nacional de Investigaciones Científicas y Técnicas \\ dperez@filo.uba.ar
}

\begin{abstract}
SUMmARY: In this paper I shall discuss McGinn's transcendental naturalism (TN) and the reasons he gives in order to show that philosophy will always be just a cluster of mysteries without answers. I shall show that the three main arguments he gives for $\mathrm{TN}$ are inconclusive and that a modular architecture of the mind he presupposes is not committed to the epistemic thesis of TN, the idea that we are "cognitively closed" to answering some questions about consciousness, meaning, knowledge and the like.
\end{abstract}

KEY WORDS: transcendental naturalism, consciousness, modularity

RESUMEN: En este trabajo discutiré el naturalismo trascendental (NT) que defiende McGinn y las razones que ofrece para mostrar que la filosofía será por siempre un cúmulo de misterios sin respuesta. Mostraré que ninguno de los tres argumentos principales que McGinn propone en favor de su posición es concluyente y que la estructura modular de la mente que presupone no está comprometida con la tesis epistémica del NT, esto es, con la idea de que estamos "cognitivamente cerrados" para responder preguntas acerca de la conciencia, el significado, la libertad, el conocimiento, etc.

PALABRAS CLAVE: naturalismo trascendental, conciencia, modularidad

Within the logical space of the possible answers to the mind-body problem, McGinn (1989) defends an extreme view according to which there is no answer to this problem, not because it is a pseudo-problem that has to be dissolved, but because it is a mystery, a genuine question without possible answers for us. This idea, labeled "Transcendental Naturalism" (McGinn 1993) or "Noumenal Naturalism" (McGinn 1989), is applied further, in McGinn 1993, to other philosophical problems such as meaning, the self, free will, the a priori, etc. According to this view, philosophy consists in a bundle of questions without answers; there is no genuine philosophical knowledge: all that philosophers have to do is to acknowledge that there are mysteries beyond our understanding, and to stop arguing in favour or against different philosophical theses; in fact, there are no philosophical theses to be supported. McGinn offers different arguments for his own view, but the core of his arguments depends upon the 
idea that we are "cognitively closed" to answer certain questions. And one of the main reasons he gives for this cognitive closure is based on a modular conception of the mind. In this paper I shall present McGinn's ideas and the reasons he gives in order to show that philosophy will always be just a cluster of mysteries without answers. I shall try to show that the arguments he offers, specially those based on a modular architecture of the mind, are inconclusive, and therefore that philosophy need not be committed to the pessimistic destiny of McGinn's dreams.

\section{McGinn's Transcendental Naturalism}

McGinn (1993) defends a theory about the nature and future of philosophy that he labels "Transcendental Naturalism" (TN). He takes as a starting point Chomsky's difference between problems and mysteries. A problem, according to this distinction, is a question about a natural phenomenon to which we can in principle find an answer because we are designed to do so, or at least because the answer is within the scope of our cognitive capacities. A mystery, in contrast, is a question that does not differ from a problem about the naturalness of the subject-matter, but whose answers are beyond our contingent cognitive capacities. ${ }^{1}$ As we can see, the distinction between problems and mysteries is relative to the cognitive capacities of the individual who is asking the question and looking for an answer: a certain question could be a mystery for a certain species (for instance, the Theorem of Thales is a mystery for a cockroach) but a solvable problem for another species (for humans, in this example). This distinction drives McGinn to claim that although we can obtain scientific knowledge by answering questions that are solvable, i.e. by solving problems, philosophical questions have no philosophical answers: they have a scientific answer (a scientific theory which explains the phenomena), but this theory is, in principle, inaccessible to us but accessible to other different cognitive non-human agents. In McGinn's words: "There is, to be sure, such a thing as philosophical ignorance but there is not such a thing as philosophical knowledge" (1993, p. 42).

Philosophy, according to McGinn, is a conceptual activity. Following Frege's distinction between sense and reference, he holds that

\footnotetext{
${ }^{1}$ McGinn (1993) also mentions two other kinds of questions: illusions (pseudoquestions, questions that suggest an answer that does not objectively exist) and issues (questions of a normative character, questions of ethics and politics). I shall set aside these two kinds of questions.
}

Crítica, vol. 37, no. 110 (agosto 2005) 
no reference ever in itself poses a philosophical problem: the objective world is philosophically unproblematic. Philosophical problems arise from the senses [the concepts] according to which we conceive the world; they are, in one good sense, purely conceptual problems. (1993, p. 41)

By varying the senses we can transform a philosophical puzzle into a scientific problem: it all depends upon the possibility of producing a conceptual shift. But - McGinn says - the concepts we have depend upon our conceptual "organs" or "faculties" or "modules", which are designed to allow us to deal with our environment, and to solve our everyday problems in the world and with other people. This is the common sense faculty, which has two parts: an intuitive physics and a folk psychology.

So, according to $\mathrm{TN}$, philosophical perplexities arise because of the limitations of our epistemic capacities, not due to the special nature of the stuff involved in philosophical questions. In order to clearly present the central theses of TN, I shall take the example of consciousness, but it is worth mentioning that McGinn formulates them for many different concepts, including the self, meaning, free will, the a priori, and also empirical knowledge. TN is a conjunction of two theses: (I) consciousness is a natural phenomenon, and its relation to the brain is also a natural relation (the metaphysical thesis), and (II) the answer to the question "how is it possible for conscious states to arise out of brain states?" is beyond our cognitive capacities: we are not able to understand this natural relation holding between the mental and the physical (the epistemic thesis).

McGinn expresses this second idea on different occasions in different ways. In McGinn 1993 (chapter 2, section 4), he holds that we cannot solve the mind-body problem without a conceptual shift, without finding a new set of concepts that can be used to understand the connection between the mind and the body, but this conceptual shift is impossible for us. We can never attain the appropriate concepts needed to transform the mystery of consciousness into a scientific, solvable problem, because "our problem is simply that we lack the necessary mental organs with which to form theories of the phenomena that puzzles us" (McGinn 1993, p. 150, my emphasis). ${ }^{2}$ I will consider this line of argument in the following sections.

${ }^{2}$ In McGinn 1991 (chapter 4), he offers another argument. He ties our ability to form concepts to the basic modes of apprehending the world that we possess, namely introspection and perception. He says: "Our perceptual access to material things, including the brain, sets limits on the way we can conceive of these things; 
On other occasions, mainly in McGinn 1989, he asserts that we are "cognitively closed" to certain questions, because our cognitive faculties are limited and they cannot allow us to answer them. ${ }^{3}$ McGinn's definition of "cognitive closure" is the following:

A type of mind $M$ is cognitively closed with respect to a property $P$ (or a theory $T$ if and only if the concept-forming procedures at $M$ 's disposal cannot extend to a grasp of $P$ (or an understanding of $T$ ) [ . . ] ; cognitive closure with respect to $P$ does not imply irrealism about $P$. That $P$ is (as we might say) noumenal for $M$ does not show that $P$ does not occur in some naturalistic scientific theory $T$-it shows only that $T$ is not cognitively accessible to $M$. (McGinn 1989, pp. 3-4)

Let us take a look to this line of argument. In McGinn 1989, he gives an a priori argument for his view. ${ }^{4}$ In the case of consciousness, McGinn holds, there are two possible ways of identifying $P$ (i.e. the natural property of the brain in virtue of which the brain is the basis of consciousness): by investigating consciousness directly, i.e. by introspection; or by studying the brain, i.e. by perception. And he argues that we will not reach $P$ by following either of these two ways. It seems quite natural to accept the first part of his argument: neither introspection nor perception could give us access to $P$. The main move he makes is to propose an argument in order to show that no inference to the best explanation nor any theoretical concept could be introduced from perception of the brain (of the physical) in order to grasp $P$. His main reason is a "certain principle of homogeneity" (McGinn 1989, p 12), which prevents a magical view of concept formation: he holds that only by analogy with physical macroscopic (spatial) cases we could create new concepts. And $P$ will not be formed like that, it is not a spatial property, and no physical property introduced in order to explain physical phenomena will

and our introspective access to consciousness sets limits on the way we can conceive of it. We need a manner of conception that abstracts radically away from these two fundamental ways of apprehending the world, but we simply have no such manner at our disposal. [...] Our concepts are infused by our basic modes of apprehending the world, and these modes of apprehension are unsuitable foundations for the kinds of concepts needed to make sense of the link between consciousness and matter" (McGinn 1991, p. 121). In my opinion, this latter thesis has no grounds at all. I do not understand in what sense "atom", "spin", or even "three" are necessarily attached to our modes of apprehending the world. I shall return to this idea later.

${ }^{3}$ The same idea is found in McGinn 1993, p. 6.

${ }^{4}$ In his 1989, McGinn only mentions Chomsky's and Fodor's theories as empirical support to his own ideas in a footnote; in my opinion, the whole paper should be read as providing a priori reasons for noumenal naturalism. 
explain how consciousness arises from the physical. In my view, this is not a good argument: there are many theoretical physical concepts (I mean: theoretical concepts belonging to physics; for example, "energy", "spin", "valence", and so on) which were not formed upon the basis of spatial analogies. In fact, in the philosophical literature there are attempts to find a realm of properties which could explain the gap between physical and phenomenal consciousness, such as Chalmers' (1993) attempt to base both phenomena on a more basic (non-spatial) phenomenon: information. It seems to me that any attempt to argue for cognitive closure has to be based on the nature of our minds, not on the nature of the concepts we actually have. So, in my opinion, the argument for TN from the specific nature of our minds is the main argument for TN. In the rest of this paper I shall be concerned with this argument.

\section{McGinn's arguments for TN}

McGinn 1993 develops three arguments in order to prove thesis (II).

\section{1}

The first argument depends upon the systematic failures of philosophical tradition to answer the question we are dealing with, in our case, the following question: "How can we explain the emergence of consciousness ( $C$-concepts) upon our brain states (physical concepts)?" McGinn claims that the answers that tradition gives us to this question form a vicious circle, the DIME circle, consisting of four paradigmatic possible answers about the explanation of the $C$ concept, none of which is definitive because they push us to the next equally unacceptable position. A $D$-position is one which holds that the $C$-concept has to be domesticated, or reduced to a set of unproblematic concepts; an $I$-position holds that $C$ is irreducible, indefinable, inexplicable, that $C$-facts are brute facts of the world; $M$-positions correspond to magical, mystical positions, such as dualism in the mind-body case; finally, $E$-positions propose that $C$ has to be eliminated. ${ }^{5}$

\footnotetext{
${ }^{5}$ I will not discuss in this section McGinn's thesis that these four are the only answers to the mind-body problem. In fact, I claim that McGinn's TN is also an answer to this problem and it is unclear if it constitutes an $I$ - or an $M$-answer or just a fifth option. My own answer to the mind-body problem tries to be an alternative answer to this circle also based on a peculiar analysis of our folk psychological concepts (see Pérez 2005a and 2005b).
} 
Let us take a closer look at this vicious circle for the case of consciousness. We take as a starting point the question "how is it possible for conscious states to arise out of brain states?" A $D$-position tries to domesticate consciousness reducing it to brain states: it holds that consciousness is nothing but a brain state. But this answer is difficult to accept because the existing link between the mental and the physical cannot be strong enough, thus there cannot be sufficient grounds for a reduction: in fact it is always possible to imagine one state without the other. This fact leads us to maintain an $I$-position, an irreducibility thesis, according to which psychophysical relations are basic correlations - brute, unexplainable facts. If we cannot explain the connection between the mental and the physical, but we think that it is inconvenient to leave unexplained something such as the mind-body relation, then we turn to $M$-positions in order to reach an explanation for consciousness: positions that postulate miracles in order to give an account of the psychophysical connection. But, according to McGinn, these miracles are nothing but "reifications of our own cognitive limitations" (1993, p. 39) and so, apparently, the only possible position turns out to be an $E$-position, an elimination of consciousness, the thesis that what cannot be explained does not exist. Finally, if it is too hard to deny the existence of a fact, like consciousness, we are led to a reductionist position (a $D$-position) once again, and the circle is reinstated. Paraphrasing Kant, we can hold that it is a scandal of the philosophy of mind that we cannot understand the exact connection holding between the mind and the brain, and that we are to accept that there is a mind-brain connection only by faith, i.e. that we have to accept the mind-brain connection as a brute fact without explanation.

TN emerges as an alternative to this circle, blocking the passage from the epistemological thesis about our cognitive limitations to the ontological thesis about the inexistence of the phenomenon that was looking for an explanation. In order to break the DIME circle, i.e. in order to prefer $\mathrm{TN}$ to any of the other four positions which constitute this circle we have to accept thesis II about the cognitive limitations of human beings, and the next two arguments lead in this direction. In any case, this first line of argument for TN, showing the inadequacies of the DIME circle, is not conclusive: the inadequacy of the philosophical answers already given does not prove that there is no answer to the problem.

It might be objected that it is not McGinn's intention to propose an argument at this point: he could be just trying to "show" the inadequacy of these philosophical options whilst not giving an argument 
against all of them, just because such an argument cannot be given: where there cannot be knowledge, there cannot be an argument either. ${ }^{6}$ But if philosophy is neither a special kind of knowledge nor a cluster of arguments, I do not know what "philosophy" means for McGinn (just a cluster of questions?). On the other hand, McGinn seems to think that there is a non-conclusive argument involved here, because he says: "Longstanding historical failure is suggestive but scarcely conclusive" (1989, p. 7, my emphasis).

It might also be objected that McGinn is not trying to prove TN on the basis of the vicious circularity of the traditional philosophical answers but, instead, that he is offering an argument to the best explanation: $\mathrm{TN}$ is the best way to understand the incapacity of philosophy (of philosophers?) to give answers to philosophical questions. ${ }^{7}$ I am not convinced of this reading of McGinn's argument. It seems to me that $\mathrm{TN}$ is also a philosophical answer to the mind-body problem (as well as to the other philosophical problems considered in McGinn 1993), and hence TN is not outside of the vicious circle of philosophical answers. What I am trying to do in this paper, if my arguments are sound, is precisely to show that TN is not a good answer to the mind-body problem and hence that we had better reconsider one or another of the answers included in the DIME circle. I have not an alternative explanation to offer of philosophical perplexities but it seems to me that McGinn's TN is not a good explanation either. If we look at the history of philosophy, we can find that many traditional philosophical problems have already received a scientific answer accessible to us, such as those about the nature of the basic constituents of the physical world, the way in which the history of the universe started, etc. McGinn has to find an asymmetry between these cases or a peculiarity of some concepts (for example, mental concepts) in order to prove his position, but I think he has not found it, or so I shall argue in this line in what follows.

2.2 .

As I said above, according to the conception of philosophy that McGinn adopts, the main argument for (II) depends upon the impossibility of producing a conceptual revolution in order to solve philosophical questions. This is the second argument that can be found in McGinn's book. In order to show the impossibility of this

\footnotetext{
${ }^{6}$ As Marcelo Sabatés argued in conversation.

${ }^{7}$ I want to thank to an anonymous referee of Crítica for pointing this possibility to me.
} 
conceptual shift, he adopts the thesis of the modularity of mind, and assumes the idea that we have a mind module or a mind organ, i.e. that we are programmed to have an intuitive theory of the mind, which produces our mental concepts, including concepts such as consciousness (in the sense of the subjective view of the mind or what it is like to be in such-and-such state), free will, agency, selfhood, etc. ${ }^{8}$ Given the fact that philosophy is a conceptual activity dealing with our common sense concepts, which are unavoidable for empirical reasons (in the same way that we cannot decide that our heart will not pump more blood), we will not be able to answer philosophical problems such as the mind-body problem by considering exclusively the concepts offered by our folk psychology module. ${ }^{9}$

The argument at this point is not conclusive, in my opinion. McGinn compares the mind module and its functioning with the intuitive physics module or the language module (McGinn 1993, chapter 1 , section 5). All of these are innately programmed in order to produce the appropriate (ordinary) concepts in order to allow a certain practice, i.e. in order to allow us to interact with other people, with the environment and to communicate with each other. But, according to McGinn, just because a certain practice is successful, it does not mean that we can answer questions formulated with the concepts involved in that practice. In McGinn's words: "we are programmed to employ concepts that are mysteries to us at a theoretical level. We can solve problems by using these concepts, but we cannot solve the problems they themselves raise" (McGinn 1993, p. 21). We can interpret McGinn's words as telling us something quite trivial: that philosophy is a conceptual activity engaged exclusively with our common sense psychological concepts, and hence that any theory involving any other kind of concept is not philosophy. There are some good reasons to interpret McGinn this way: as I said above, for McGinn, philosophy is a conceptual activity. He also says that referents do not generate philosophical problems, only senses can. But according to this interpretation of McGinn's argument, the limitations that TN postulates are not a consequence of our contingent

\footnotetext{
${ }^{8}$ See next section for a discussion about this empirical assumption about the modularity of mind.

${ }^{9}$ This last paragraph is a reconstruction of McGinn's ideas. I will not discuss his assumptions at this stage of the paper. In this section I want to highlight the fact that even if we have a theory of the mind module (a really disputable thesis, see next section), and even if it "produces our ordinary mental concepts" as McGinn says, it is not necessary to draw from these facts the conclusion that we are unable to propose a scientific theory of mental phenomena.
} 
mental capacities, but a consequence of a stipulation about what philosophy is. If "solving the mind-body problem" involves finding a certain property $P$ which does not belong to the mind module, and philosophy is only concerned with the concepts produced by this organ, then the solution to the mind-body problem is outside the reach of philosophy due to the peculiar characterization of philosophy that McGinn adopts.

This interpretation of McGinn's argument at this point is not satisfying. In my opinion, we have to propose another interpretation of McGinn's argument. It has to be thought of as a stronger argument: McGinn has to maintain that it is impossible to formulate a theory about mental phenomena using exclusively the mental concepts that the corresponding module generates, and also that we cannot add other different new concepts, or change our folk concepts, in order to formulate such a theory. But if this were the case, it seems to me that not only the mind but also the physical phenomena involved in our intuitive physics, and the phenomenon of language involved in our everyday linguistic practice, would remain a mystery forever. However, McGinn holds that in these latter cases a conceptual shift has been in fact produced and that we do have a new set of concepts available in terms of which we have actually proposed a successful physical and linguistic theory. Therefore, McGinn has to prove that there is an asymmetry between physics and linguistics, on the one hand, and psychology/a naturalistic explanation of the mind, on the other hand. But this asymmetry cannot be based on a difference about the naturalness of the subject matter (according to $\mathrm{TN}$ ), so we need an argument in order to show that only in the case of mental concepts can the conceptual shift necessary for an explanation not be produced.

\section{3 .}

The third and last argument claims that there cannot be another organ, the "faculty of reason" which could produce the conceptual shift we are looking for. ${ }^{10}$ According to McGinn, this faculty is responsible for our theoretical knowledge of the world, including all our scientific knowledge, i.e. the knowledge that goes beyond our common sense theories. McGinn describes this "organ" in these words:

\footnotetext{
${ }^{10}$ McGinn also calls it "reasoning faculty" or "intellectual organ".
} 
Among these semantic organs [of human beings] are those that implicate consciousness in their operations. [...] Chief among these is the organ we call "reason" — which no doubt itself decomposes into a number of sub-organs or systems. At a first level of approximation, we can characterize it as the organ by means of which we form conscious beliefs, on the basis of evidence, about a wide variety of subject-matters; in particular, it is the organ responsible for what we think of as our theoretical knowledge of the world. We use it, among other things, for doing philosophy: it is the organ deployed in the search for the kind of truth proper to that designation. (McGinn 1993, pp. 126-127)

McGinn speculates that the faculty of reason has a CALM (combinatorial atomism with lawlike mappings) mode of thought, which clearly fits certain domains such as physics, linguistics, and mathematics (1993, p. 19), but cannot help us with other things like consciousness, free will, etc. ${ }^{11}$ The CALM conjecture postulates that there are some subject-matters that could be successfully thought of as a set of primitive elements, arranged by a set of combinatorial principles, a set of "stateable laws or rules", which generate all the possible relations between the elements. According to McGinn "CALM theories are the natural inhabitants of our human cognitive space" (p. 129). But, McGinn holds, "the entities and relations that prompt philosophical perplexity are not construable in the CALM style" (p. 130, my emphasis), and hence philosophical questions will not be solved by this faculty of reason, applying its CALM treatment to these questions. McGinn's idea at this point is that it is impossible to explain conscious states in terms of mereological notions from brain states: more and more physical phenomena will not explain our mental life.

I have two concerns about this argument. In the first place, even granting that we have a "faculty of reason" and that it has a CALM structure (I shall discuss this point in the next section), there is no argument which could prove that this CALM strategy, successful for certain domains, has to be extended to every other possible domain: it is not inconceivable that there could be other kinds of thought-structures suitable for other kinds of domain. McGinn does not show that the "faculty of reason" is the only organ available in our minds that might be used to solve certain kinds of questions.

Secondly, McGinn's argument at this point has changed the target: he argues that a CALM structure cannot be applied to philosophical

\footnotetext{
${ }^{11}$ McGinn recognizes that this is a highly speculative hypothesis (1993, p. 129). He develops this hypothesis in chapter 1 , section 4 and in chapter 8 , section 1 .
} 
questions because of the nature of the phenomena (p. 135) or the entities and relations (p. 130) involved. But TN is not a thesis about the special nature of the entities involved in philosophical puzzles; on the contrary, TN holds that there is nothing special about the referents of the concepts involved in philosophical perplexities; they are absolutely natural phenomena. In the next section I shall come back to the CALM hypothesis.

\section{McGinn's "Modules"}

There are many difficulties in McGinn's line of argument and I have mentioned some of them in the last section. He offers a priori arguments for TN which, as I tried to show, are inconclusive. There are no a priori reasons to assume that there is a limit to our conceptformation capacities and, hence, there are no a priori limits for our cognitive capacity to solve problems. But if philosophical problems do not constitute a special kind of problems that forbid their own solutions, and if there are no a priori limitations to our cognitive abilities to solve such problems, there still is the possibility that we are empirically limited to solve such problems. Maybe our cognitive architecture is such that philosophical problems lie outside their reach because of the way in which our human minds are in fact constituted.

In this section, I shall identify some difficulties concerning the empirical assumptions McGinn makes about the functioning of the mind. McGinn 1993's arguments are based on a modular architecture of the mind. My objection to McGinn is two-fold. First, it is not obvious that the modular architecture of the mind entails the kind of pessimism that McGinn defends. ${ }^{12}$ Second, it is not clear how McGinn thinks modules have to be characterized; the only characterization of modules that McGinn gives is that they are "special purpose domain specific systems" (McGinn 1993, p. 6), but there are

\footnotetext{
${ }^{12}$ It is true that the modularity of the mind, as Fodor conceives it, entails a certain pessimism about the future of computational psychology. He holds that certain $\operatorname{cog}$ nitive processes cannot be computationally understood (all the "central processes"), and that they will always be beyond the reach of cognitive psychology. But the kind of pessimism that McGinn tries to ground on the modularity of mind is quite different; it is a substantial pessimism about a certain discipline; he holds that we would never have philosophical knowledge. It is a different pessimism from Fodor's, who argues just for the impossibility to understand certain cognitive processes in computational terms, without claiming that we are cognitively closed (in an absolute sense) to a certain domain of phenomena.
} 
many different ways of conceiving modules and the modular architecture of the mind. In this section, I shall consider two paradigmatic views on modules: Fodor's characterization of modules as opposed to central system processes, and Pinker's massive modularity view of the mind. I take these two proposals (1) because they are two competing hypotheses still alive nowadays (see Fodor's discussion of Pinker's ideas in Fodor 2000, for example); (2) because Fodor 1983 is the classic work to be quoted in this field; and (3) because Pinker 1997 explicitly adopts McGinn's ideas while discussing the status of philosophy within his theory. I shall try to show that McGinn's TN cannot be held either by adopting Fodor's on modules view nor on Pinker's, although the latter seems more congenial with McGinn's ideas. $^{13}$

According to Fodor (1983), information from the external world passes through sensory transducers that transform the data into special formats - different formats for different modules. Each module can process only its own inputs, with their special format. After internal (computational) processing, each module outputs data in a common format suitable for central, domain general processing. Modules are precisely characterized by a set of features. According to Fodor (1983), modules have the following characteristics: (1) they are domain specific; (2) their operation is mandatory, i.e. they are obligatorily applied; (3) the central access to the representations that the module computes is limited; (4) they are fast, the cognitive capacities involved in their functioning are minimal; (5) they are encapsulated - this is one of the central features of Fodor's modules-, the computations that occur within the module are immune to any information beyond the specific information belonging to that module;

\footnotetext{
${ }^{13}$ Fodor's and Pinker's are not the only views on modularity existing nowadays. In fact, McGinn is probably thinking in terms of Chomsky's view about the language organ, because he adopts Chomsky's characterization of module as a "special-purpose domain-specific system". But Chomsky's view is quite imprecise if we go beyond the language faculty: he does not offer a general characterization of mental "organs" or "modules" beyond the language faculty, nor an exahustive "list" of plausible mental organs. McGinn seems to me to be extending Chomsky's view jumping from his empirical theory to the philosophical void. In this section, I am trying to find a more precise and plausible general view of the notion of modularity and of the modular architecture of the mind (analyzing Fodor's and Pinker's views) in order to fill this void. It is important to highlight that the characterization of "organ" that Chomsky proposes and McGinn adopts is too wide, and it does not compell us to accept the consequences about the CALM mechanism and the faculty of reason that McGinn draws, if we do not add some further constraints to this definition of "module". This is the reason why it seems to me convenient to examine other more specific proposals such as Fodor's and Pinker's.
} 
(6) input analyzers have "shallow" outputs; (7) modules have a fixed neural architecture; (8) modules exhibit characteristic and specific breakdown patterns; and (9) their ontogeny has a characteristic pace and sequencing (Fodor 1983, chapter 3). The essential features of modules are (1) and (5), according to Fodor's most recent view (see his 2000). Note, however, that McGinn's definition of modules does not include (5); hence McGinn's modules seem not to be the same as Fodor's.

Fodor mentions some examples of modules postulated by cognitive science: mechanisms of color perception, for the analysis of shape, and for the analysis of three-dimensional spatial relations, the perceptual recognition of sentences, face recognition, etc. But this list does not coincide with McGinn's, who mentions the following components/modules of the mind: language, common sense (including intuitive physics and folk psychology), science, mathematics, and philosophy (McGinn 1993, p. 22).

Fodor accepts that most of our cognitive mind is not modular: many mental processes depend upon the central system which is isotropic and Quinean and not computational, hence current cognitive psychology cannot tell us anything about the processes going on there. It is not clear whether McGinn would accept the idea that besides modules there has to be some non-modular central system, but in any case it seems to me that it cannot be described as McGinn describes "reason" appealing to the idea of a CALM structure, because this kind of structure seems to be computationally describable.

Pinker 1997, on the other hand, develops a theory of the mind based on two main ideas: the theory of natural selection and the computational theory of the mind. He defends the view that our minds are constituted by a large set of modules, resulting from the process of natural selection. ${ }^{14}$ The list of phenomena that he wishes to explain from this perspective is impressive: vision, emotions, common-sense theories (including mathematics, physics, biology, a theory of the mind, logic, and probabilities), family values, art, religion and phi-

\footnotetext{
14 "The mind is organized into modules or mental organs, each with a specialized design that makes it an expert in one arena of interaction with the world. The module's basic logic is specified by our genetic program. Its operation was shaped by natural selection to solve the problems of the hunting and gathering life led by our ancestors in most of our evolutionary history. The various problems for our ancestors were subtasks of one big problem for their genes, maximizing the number of copies that made the next generation. In this view, psychology is engineering in reverse" (Pinker 1997, p. 21).
} 
losophy. ${ }^{15}$ Science is an exception. Pinker acknowledges that we are not designed to be good scientists, because (1) our intelligence is ecological, i.e. it is designed to solve problems with a certain content, it does not naturally produce abstract algorithms which could be applied to every domain, (2) science is expensive, it is hard for us to grasp knowledge about the entire world beyond the reach of our hands and sight, and (3) our brains were shaped for fitness, not for truth. ${ }^{16}$

Although Pinker uses the word "module" in order to describe his view, he doubts that it is the correct word. In fact he uses different words in order to explain his ideas, including "modules", "mental organs", "society of experts", and "innate intuitive theories". These modules are different from Fodorian ones, because they are not necessarily encapsulated (Pinker 1997, p. 315); Pinker also admits that some of the algorithms that constitute the modules are wired into the brain during child development. ${ }^{17}$ If we compare Pinker's list of phenomena, explained by the existence of modules, it does not coincide with McGinn's. It is important to note that according to neither Fodor or Pinker is there a faculty (or a module) of theoretical reasoning.

Besides the inadequacy of McGinn's ideas about the modularity of mind with these two exemplar views in the recent literature, there are additional problems with McGinn's ideas about the functioning of our minds. It is widely held nowadays, as McGinn holds, that folk psychology is "a specialized subsystem of the mind equipped with its own distinctive principles and programme of developmental expression, as well as a specific biological purpose" (McGinn 1993,

${ }^{15}$ The ideas that Pinker proposes about philosophy at the end of his book are borrowed from McGinn's work (1989, 1993).

16 "Natural selection [...] did not shape us to earn good grades in science class or to publish in refereed journals. It shaped us to master the local environment, and that led to discrepancies between how we naturally think and what is demanded in the academy" (Pinker 1997, p. 302).

17 "Stereo vision does not come free with the two eyes; the circuitry has to be wired into the brain" (Pinker 1997, p. 237). "Learning is often described as indispensable shaper or amorphous brain tissue. Instead, it might be an innate adaptation to the project-scheduling demands of a self-assembling animal. The genome builds as much of the animal as it can, and for the parts of the animal that cannot be specified in advance $[\ldots]$ the genome turns on an information-gathering mechanism at the time in development at which it is most needed" (Pinker 1997, p. 241). These quotations make me think that he is closer to Karmiloff-Smith (1992) and the idea that there is a process of modularization during development, than to the idea of definitively structured innate modules, defended by Fodor. 
p. 22). Some people draw an analogy between the faculty of language and folk psychology from this description and some accepted facts about our folk psychology; for example, that it constitutes a rich system of knowledge, easy to learn, in fact not taught but learned upon fragmentary and poor data, like natural languages. Following this analogy some theorists conceive our folk psychology as a cognitive or conceptual organ, i.e. as having a modular structure like our linguistic competence. In the last decade there has been a great deal of discussion about this possibility (see, for example, Carruthers and Smith 1996, specially part II) and the question is far from having a definitive answer. Maybe McGinn's arguments for TN should be construed as taking as a starting point the idea that folk psychology is one of our conceptual modules, and deriving from this fact the impossibility of avoiding the concepts involved in the functioning of this module, and also the impossibility of theorizing about the mind from outside this module, i.e. the impossibility of appealing to another set of concepts to understand mental phenomena. But even in the case that we accept that our folk psychology constitutes one of our conceptual modules (which, I insist, is widely discussed), the pessimism about philosophy that McGinn holds does not follow from this fact.

In the first place, it is not clear that the output of the common sense module (if we accept, for the sake of the argument, that there is something like that) should be our common sense psychological concepts, usually the modularity thesis does not state that the outputs of modules are concepts. And even if this were the case, it is not clear why McGinn thinks that certain concepts, basically those generated by the mind module: consciousness, self, meaning, etc., are involved in unsolvable philosophical mysteries, while other concepts generated by other modules, such as "physical object", "time", "space", etc., are scientifically accessible and, hence, the questions posed around them are solvable. It seems that McGinn thinks that the only genuine philosophical questions are those involving the mind either directly or indirectly, but, there are also genuine philosophical problems such as the nature of physical objects, the notion of event, the individuation criteria for both, the problem of identity through time, etc., which do not involve any mental notions. ${ }^{18}$ So, McGinn's conception of philosophy restricts the scope of this discipline in an arbitrary way.

${ }^{18}$ At least not obviously. It has to be argued for, if we think they do. 
In a more general way, it is not clear what the relation is between the concepts (psychological or physical) generated by the common sense modules and the activity of the "reason module", which generates, on the one hand, unsolvable mysteries and, on the other hand, genuine problems that are solvable by scientific inquiry. In other words, I can see no reasons why there could be a theoretical approach to some phenomena which involves the functioning of some modules, such as a scientific study of language (which involves the functioning of the language faculty), and physics, i.e. the scientific study of physical phenomena (phenomena that are also described by the common sense physical module, if we accept the idea that there are conceptual modules). McGinn gives the following reason: "there is no general expectation that the concepts available to one component [of the mind] will be transferable to another. It may thus be that folk psychological concepts are inherently resistant to any kind of theoretical understanding proper to the reflective faculties of the mind" (1993, p. 22). But taken literally, this thesis is too strong: it entails not only pessimism about philosophy, but also about any kind of reflection on the functioning of any module. There are no foundations for an asymmetry between the concepts that emerge from the "mind module" and the concepts that emerge from other modules. ${ }^{19}$

Finally, the idea that there is a faculty of reason, with a CALM structure, is just a highly speculative hypothesis with no empirical support either from Fodor's or from Pinker's ideas about the modularity of mind. ${ }^{20}$ As we saw above, Pinker refuses to consider science as an activity dependent upon a naturally selected module. Fodor, on the other hand, includes science among the processes belonging to the central processor, and hence he is pessimistic about explaining its functioning by the computational theory of mind: it seems clear that Fodor would not accept the idea that central processes have a CALM structure. It seems to me that McGinn would prefer a massive modularity thesis (refusing the Fodorian distinction between central processors and modules), treating the faculty of reason as a module among the others. He explicitly says that reason "is simply one system among many, with its own purposes and limitations, its own

\footnotetext{
${ }^{19}$ It is also debatable that philosophy has to be exclusively a conceptual activity, dealing only with concepts and ignoring references. If we adopt a Quinean view of philosophy, accepting that it is continuous with science, the idea that science is an enterprise qualitatively different from philosophy is doubtful.

${ }^{20}$ It is clear that there are so many differences between McGinn's "faculty of reason" and Chomsky's "science-forming faculty" that it is easy to see that they cannot be talking about the same "organ" (see Chomsky 1994, specially pp. 82-83).
} 
domain of efficient operation" (p. 137). But he owes us an explanation about what is exactly its own specific domain of operation, and why it could deal with physical phenomena or linguistic phenomena but not with mental phenomena if we accept, as he does, that all these kinds of phenomena are perfectly natural phenomena. Moreover, he has to explain how this organ could operate over the outputs of different modules and, in general, how the different modules are connected. It seems to me that one way or another the different modules have to be connected: we can talk and write about our mental states, we can count and quantify physical objects, and we can theorize about different domains: physical objects, psychological phenomena, our linguistic competence, etc. Finally, as I said above, a massive modularist like Pinker does not defend the idea that there is a theoretical module, with a CALM structure, as McGinn needs in order to defend his TN; on the contrary, he denies its existence. Summing up, if I am right in the objections I have raised about McGinn's theory, modularity and pessimism about philosophy are not essentially connected as he thinks.

\section{Conclusion}

In this paper I have tried to show that McGinn's arguments for TN are inconclusive both from an a priori and also from an empirical point of view. I have shown that the three main arguments he gives for TN are inconclusive (section 2) and that a modular architecture of the mind is not committed to the epistemic thesis of TN, the idea that we are "cognitively closed" to answering some questions about consciousness, meaning, knowledge and the like (section 3). I believe that McGinn's position is right about naturalism, the ontological thesis (I), which holds the natural character of these phenomena. But I believe, following Quine, that "knowledge, mind and meaning are part of the same world they pertain to, and that they are to be studied in the same empirical spirit that animates natural science" (Quine, 1969, p. 26, my italics). I hope I have shown that there are no good reasons to think otherwise. ${ }^{21}$

${ }^{21}$ I want to thank Liza Skidelsky for helpful discussions on these topics, and Marcelo Sabatés, who first talked to me (enthusiastically) about McGinn's TN. I also want to thank our philosophy of mind research group (including S. Español, A. Hulton, K. Pedace, E. Rabossi, E. Santilli, N. Stigol and J. Vergara), where I first presented these ideas; and J. Corbí, L. San Juan and M. Moreno for a helpful discussion while presenting these ideas at the University of Valencia. Previous versions of this paper have been read at the Eighth International Colloquium on 


\section{REFERENCES}

Carruthers, P. and P. Smith, 1996, Theories of Theories of the Mind, Cambridge University Press, Cambridge.

Chalmers, D., 1996, The Conscious Mind, Oxford University Press, Oxford.

Chomsky, N., 1994, "Naturalism and Dualism in the Study of Language and Mind", reprinted in N. Chomsky, (2000), New Horizons in the Study of Language and Mind, Cambridge University Press, Cambridge, pp. 75105.

- 1976, Reflections on Language, Fontana, Glasgow.

Fodor, J., 2000, The Mind Doesn't Work That Way, MIT Press, Cambridge.

- 1983, The Modularity of Mind, MIT Press, Cambridge.

Karmiloff-Smith, A., 1992, Beyond Modularity: A Developmental Perspective on Cognitive Science, MIT Press, Cambridge.

McGinn, C., 1993, Problems in Philosophy, Blackwell, Oxford.

- 1991, The Problem of Consciousness, Blackwell, Oxford.
, 1989, "Can We Solve the Mind-Body Problem?", Mind, vol. 98, pp. 349-366.

Pérez, D., 2005a, "El problema mente-cuerpo reconsiderado", Daimon, vol. 34, pp. 97-110.

— 2005b, "Mental Concepts as Natural Kind Concepts", in M. Ezcurdia, R. Stainton and C. Viger (eds.), New Essays in Philosophy of Language and Mind, Canadian Journal of Philosophy, vol. suppl. 30, University of Calgary Press, Calgary.

Pinker, S., 1997, How the Mind Works, W.W. Norton and Co., New York.

Quine, W.V.O., 1969, Ontological Relativity and Other Essays, Columbia University Press, New York.

Received: February 24, 2004; revised: June 15, 2005; accepted: August 24, 2005.

Cognitive Science, San Sebastián, Donostia, Spain, May 7-10, 2003, and at the Second "Language, Mind and World" Conference, Buenos Aires, Argentina, May 26-29, 2003. A special acknowledgment to the two anonymous referees of Crítica for their helpful comments on a previous version.

Crítica, vol. 37, no. 110 (agosto 2005) 